\title{
Repulsions Ball in Table Tennis
}

\author{
Dusko Bjelica' , Marina Vukotic', Jovan Gardasevic ${ }^{1}$ \\ 'University of Montenegro, Faculty for Sport and Physical Education, Niksic, Montenegro
}

\begin{abstract}
The purpose of this research was to conclude how height and time of the duration of a bounce of table tennis ball are in the relation with prescribed (standard) pressure. The recording was performed by a professional digital rapid-cinocamera. The ball was released from the height of nine meters on a flat, solid surface. The surface of the collision was measured with portable contrast colours of the ball and surface before the collision with the surface and measurement of the surface prints on the ball and surface after the bounce. No matter how many times the ball was moving vertically down in free fall it did not have vertical rebound of four successive bouncing. The existance of ball asymmetry and consequences of that asymmetry predominantly had a negative effect on the determination of the height of culmination points. To establish certain legality in the repulsion of table tennis ball it is necessary to define two sizes: the spacial or height of culmination point of the ball of each rebound from one side, and time or the moment of the rebound of the ball on the other side. We can conclude that by the observation of the sum of the path from the moment of release to culmination point of the fourth rebound of the ball, the path and total duration of the four successive bouncing mostly depends on prescribed pressure.
\end{abstract}

Key words: Table Tennis, Table Tennis Ball, Bounce

\section{Uvod}

U današnjim uslovima života, sport predstavlja veoma važno područje u kojem čovjek na specifičan način može ispoljiti svoje, prije svega, stvaralačke kretne strukture (Bjelica i Fratrić, 2011). U okviru programa fizičkog razvoja igre imaju dominantnu ulogu, a među svim igrama najatraktivnije su igre loptom (Bjelica, 2014; Bjelica, Popović, \& Gardašević, 2016b). Igre sa loptom postavljaju velike metaboličke zahtjeve za igrače (Bjelica, Popović, \& Gardašević, 2016a) koji se karakterišu brojnim i raznovrsnim kompleksnim dinamičkim kineziološkim aktivnostima koje karakteriše veliki broj cikličnih (Gardašević, Vasiljević, i Bojanić, 2015; Bjelica, Popović, i Gardašević, 2016c; Bjelica, Popović, i Gardašević, 2016d, Sermaxhaj, Popović, Bjelica, Gardašević, i Arifi, 2017; Gardašević, Bjelica, \& Vasiljević, 2017a; Gardašević, Bjelica, \& Vasiljević, 2017b) i acikličnih kretanja (Gardašević, Bjelica, Milašinović, i Vasiljević, 2016). U dobrom meču, svaki igrač čini mnogo elementarnih kontrakcija na terenu, pružajući niz složenih pokreta, na osnovu čega su igrači morali razviti osnovne i specifične motoričke sposobnosti osobine (Bjelica, Popović, Tanase, \& Gardašević, 2017). S obzirom da se ova- kav manevar odvija kontinuirano i dugotrajno, pored toga savremeni manevar, gdje već postoje dobro usklađene kombinacije, vrši se u optimalnoj brzini i u stanju maksimalnog zamora (Bjelica et al., 2016c). Sinteza pokreta u svakom dinamičkom stereotipu mora biti vrlo precizna. Svaki dinamički stereotip, mora tehnički skoro savršeno da se izvede u najvećoj brzini kretanja i sa najvećim stepenom zamorenosti (Bjelica, 2014).

Stoni tenis predstavlja sport u kome se takmiče dva ili četiri igrača, veoma je zanimljiva igra i brzo je prihvaćena širom svijeta (Zagatto, Kondrić, Knechtle, Nikolaidis, \& Sperlich, 2017). Rezultat meča stoni tenisa nije ocijenjen na nivou motoričkih performansi, niti ko je trčao duže, ili ko je trčao brže, ili ko je skočio više, već po broju poena. To je je izuzetno dinamična i brza igra, koja bogatstvom pokreta spada u red polistrukturalnih sportskih igara (Bjelica, 2005). Stoga, svi manevarski pokreti tokom igre su podređeni kretanju lopte (Bjelica, Popović, Gardašević, \& Krivokapić, 2016). Lopte su kuglastog oblika, ispunjene vazduhom i sa većim pritiskom od atmosferskog (Bjelica, 2014; Bjelica \& Gardasevic, 2018). Najvažniji rekvizit svih igara je lopta (Karimi, Kudo, Razaghi,

Correspondence:

\section{Montenegro M. Vukotic}

Gport University of Montenegro, Faculty for Sport and Physical Education, Narodne omladine bb, 81400 Niksic, Montenegro E-mail: marinavuk@ac.me 
\& Navidbakhsh, 2015). Danas se proizvode sve vrste lopti čija se konstrukcija približava punoj simetriji, međutim, idealna simetrija lopte još nije dostignuta. Lopta je mašina, čijih svojstava svaki igrač mora biti u potpunosti svjestan (Bjelica, 2008).

Cilj ovog istraživanja je bio da se utvrdi kakvi u visina i vrijeme trajanja odskoka stonoteniske lopte u odnosu na propisani (standardni) pritisak.

\section{Metod}

Istraživanje je sprovedeno sa stonoteniskom loptom koja je definisana određenim veličinama (Tabela 1.).

Tabela 1. Dimenzije stonoteniske lopte

\begin{tabular}{cccccc}
\hline $\begin{array}{c}\text { Masa } \\
(\mathbf{k g})\end{array}$ & $\begin{array}{c}\text { Poluprečnik } \\
(\mathbf{m})\end{array}$ & $\begin{array}{c}\text { Obim } \\
(\mathbf{m})\end{array}$ & $\begin{array}{c}\text { Poprečni presjek } \\
(\mathbf{m})\end{array}$ & $\begin{array}{c}\text { Površina } \\
(\mathbf{m})\end{array}$ & $\begin{array}{c}\text { Zapremina } \\
(\mathbf{m} \mathbf{3})\end{array}$ \\
\hline 0.00385 & 0.01885 & 0.1185 & 0.001116 & 0.004465 & 0.000028 \\
\hline
\end{tabular}

Kuglasti oblik lopte je izabran zbog toga što se smjer kretanja lopte, nakon njenog odbijanja od podloge, može predvidjeti. U odnosu na ostala geometrijska tijela, specifičnost lopte je u tome što loptasto tijelo svoju zapreminu zatvara najmanjom površinom, što je lako utvrditi. Sva izračunavanja nepobitno potvrđuju da je svaka masa, ako je ukomponovana u loptasti oblik, zahvata najmanju površinu. Standardna stonoteniska lopta je stvorena (sa manjim odstupanjima) određenim veličinama sa puno simetrije od licenciranog proizvođača.

Ovo istraživanje jer sprovedeno snimanjem kamerom slobodnog pada lopte i serije odskoka lopte nakon odbijanja od čvrste podloge. Snimanje je vršeno profesionalnom digitalnom rapid-kinokamerom JVC GI-HM750E sa pedeset snimaka u sekundi i ekspozicijom sek/100. Lopta je puštena na ravnu čvrstu podlogu sa visine od devet metara. Površina sudara lopte sa čvrstom podlogom se određivala prenosnom kontrasnom bojom lopte i podloge prije sudara sa tlom i mjerenje površine otisaka na lopti i podlozi nakon odskoka. U slučaju sudara lopte u padu sa čvrstom podlogom, sila sudara zavisi od mase tijela koje se kreće i ubrzanja koje ima padajuće tijelo u trenutku sudara. Sudar elastičnih tijela odvija se u dvije faze. U prvoj fazi se materija sudarenih tijela sabija, pa se ta faza zove period sabijanja ili kompresija. Zbog elastičnih osobina materija u sudaru, nakon kompresije odvija se druga faza sudara, koja se zove period vraćanja na prethodno stanje ili restitucija.

Prilikom samog postupka spuštanja stonoteniske lopte vazduh je bio pod propisanim (standardnim) pritiskom. U toku snimanja kamera je bila potpuno imobilisana. U projekciji kretanja lopte bili su izmjereni (u metrima) markeri, radi određivanja razmjere (R) između veličina na ekranu i realnih veličina (ekran $\mathrm{R}$ veličine prirodne i ekranske). Vrijeme trajanja kretanja mjereno je u sekundama. U obradu uzete su pozicije pada lopte i četiri odskoka. Izmjereno je vrijeme pređenog puta između svake pojedinačne pozicije. Na osnovu tih podataka izmjereni su put, brzina i ubrzanje za loptu u svakom snimljenom trenutku. U daljoj obradi sirovog materijala, prikazanog u rezultatima ovog istraživanja, izračunati su svi relevantni podaci, na osnovu kojih se repulzija, odnosno odskoci lopte sa punom simetrijom mogu kvantitativno izračunati. Svaki slobodni pad grafički će biti prikazan određenim sistematizovanim dijagramom.

\section{Rezultati}

Prostornovremenski parametari repulzije stonoteniske lopte sa punom simetrijom prikazani su u Tabeli 2 .

Tabela 2. Prostornovremenski parametari repulzije stonoteniske lopte

\begin{tabular}{clc}
\hline & Prostorno vremenski parametri & vrijednosti \\
\hline h1 & Visina slobodnog pada (m) & 9.00 \\
t1 & Vrijeme trajanja prvog padanja (s) & 1.26 \\
t2 & Vrijeme trajanja prvog penjanja (s) & 0.50 \\
h2 & Visina prvog odskoka (m) & 1.89 \\
t3 & Vrijeme trajanja drugog padanja (s) & 0.50 \\
t4 & Vrijeme trajanja drugog penjana (s) & 0.30 \\
h3 & Visina drugog odskoka (m) & 1.13 \\
t5 & Vrijeme trajanja trećeg padanja (s) & 0.42 \\
t6 & Vrijeme trajanja trećeg penjanja (s) & 0.30 \\
h4 & Visina trećeg odskoka (m) & 0.80 \\
t7 & Vrijeme trajanja četvrtog padanja (s) & 0.28 \\
t8 & Vrijeme trajanja četvrtog penjanja (s) & 0.24 \\
h4 & Visina četvrtog odskoka (m) & 0.50 \\
\hline
\end{tabular}

U prvoj fazi, Dijagram 1. prikazuje faze prostornovremenskih parametara repulzije stonoteniske lopte sa punom simetrijom i četiri odbijanja odskoka od čvrste površine, zavisno od standardnog pritiska lopte. U vertikalnoj osi su prikazane kulminacione tačke svakog odskoka mjerene $\mathrm{u}$ metrima, a u horizontalnom dijelu vrijeme trajanja svakog odskoka prikazano je u sekundama. 


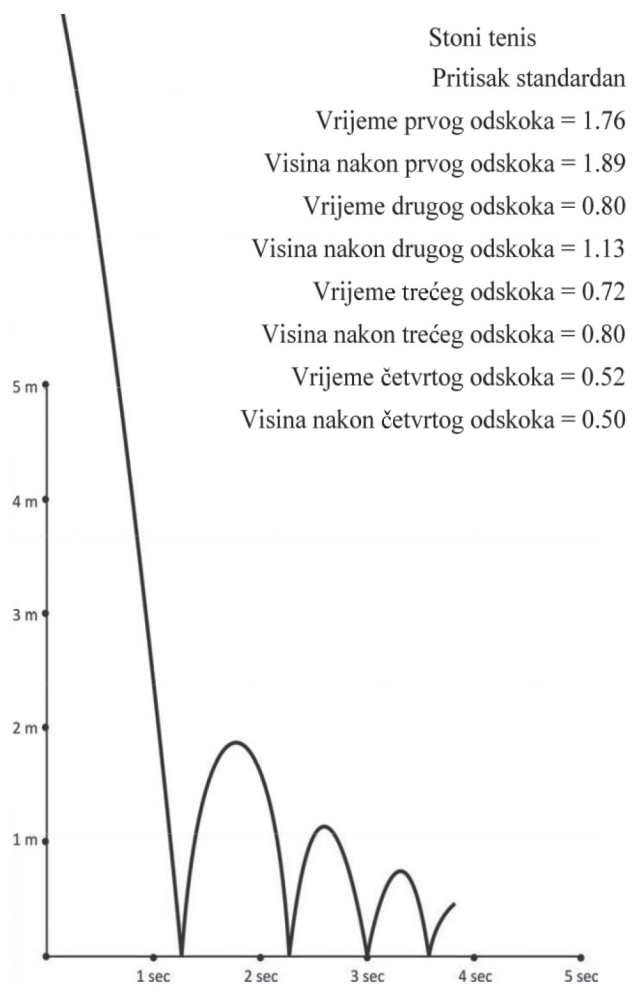

Dijagram 1. Vrijeme i visina odskoka (standardni pritisak lopte)
U drugoj fazi prikazan je interpolirani dijagram vremena trajanja pojedinačnih odskoka u funkciji pređenog puta sa upisanim podacima na Dijagramu 2.

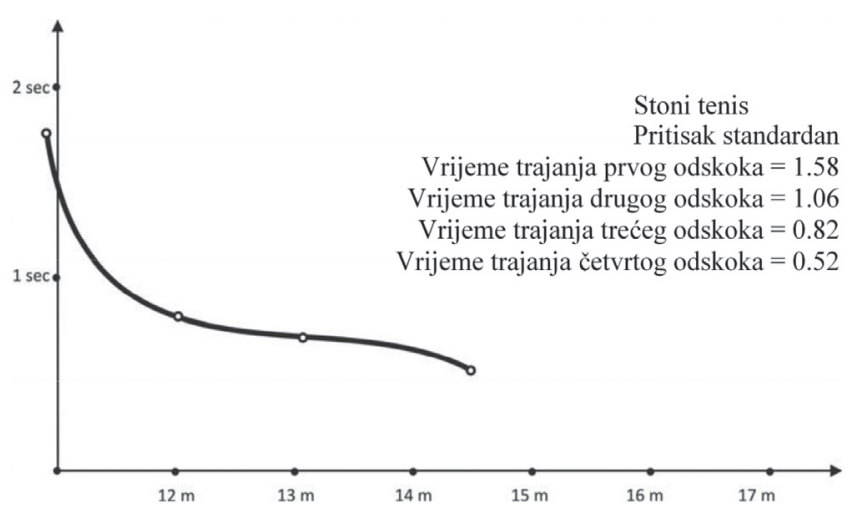

Dijagram 2. Trajanje odskoka (standardni pritisak lopte)

Na Dijagramu 3. je prikazan interpolirani dijagram kulminacionih tačaka pojedinačnih odskoka u funkciji vremena, sa upisanim podacima.

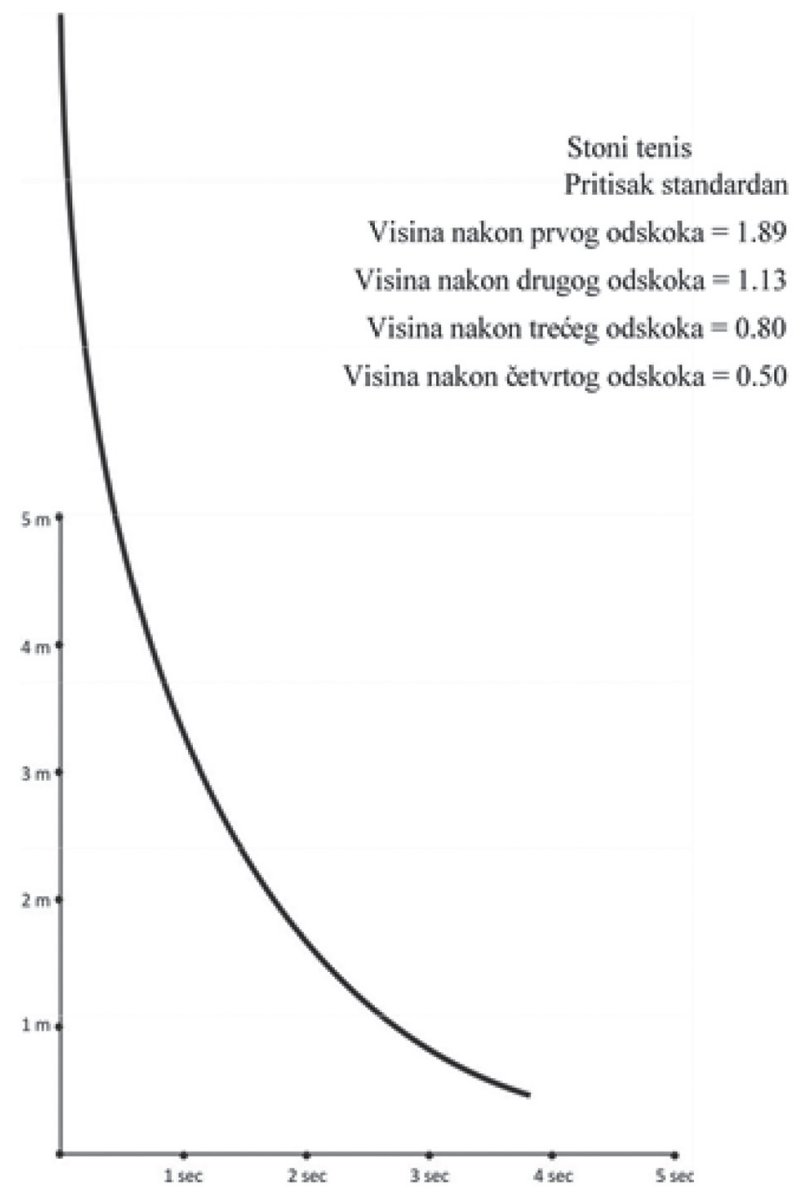

Dijagram 3. Visine odskoka (standardni pritisak lopte) 
U sledećoj fazi su prikazani indeksi ukupnog vremena trajanja i pređenog puta za stonotenisku loptu za četiri odskoka (Tabela 3.).

Tabela 3. Indeks ukupnog vremena trajanja i pređenog puta za stonotenisku loptu za četiri odskoka

\begin{tabular}{lccc}
\hline & Pređeni put & Vrijeme trajanja & Indeks=put/vrijeme \\
\hline Nakon prvog odskoka & 10.89 & 1.76 & 6.188 \\
Nakon drugog odskoka & 12.02 & 2.56 & 4.695 \\
Nakon trećeg odskoka & 12.82 & 3.28 & 3.909 \\
Nakon četvrtog odskoka & 13.32 & 3.80 & 3.505 \\
\hline
\end{tabular}

Na Dijagramu 4. je prikazano ukupno vrijeme trajanja, ukupni pređeni put i indeks pritiska stonoteniske lopte.

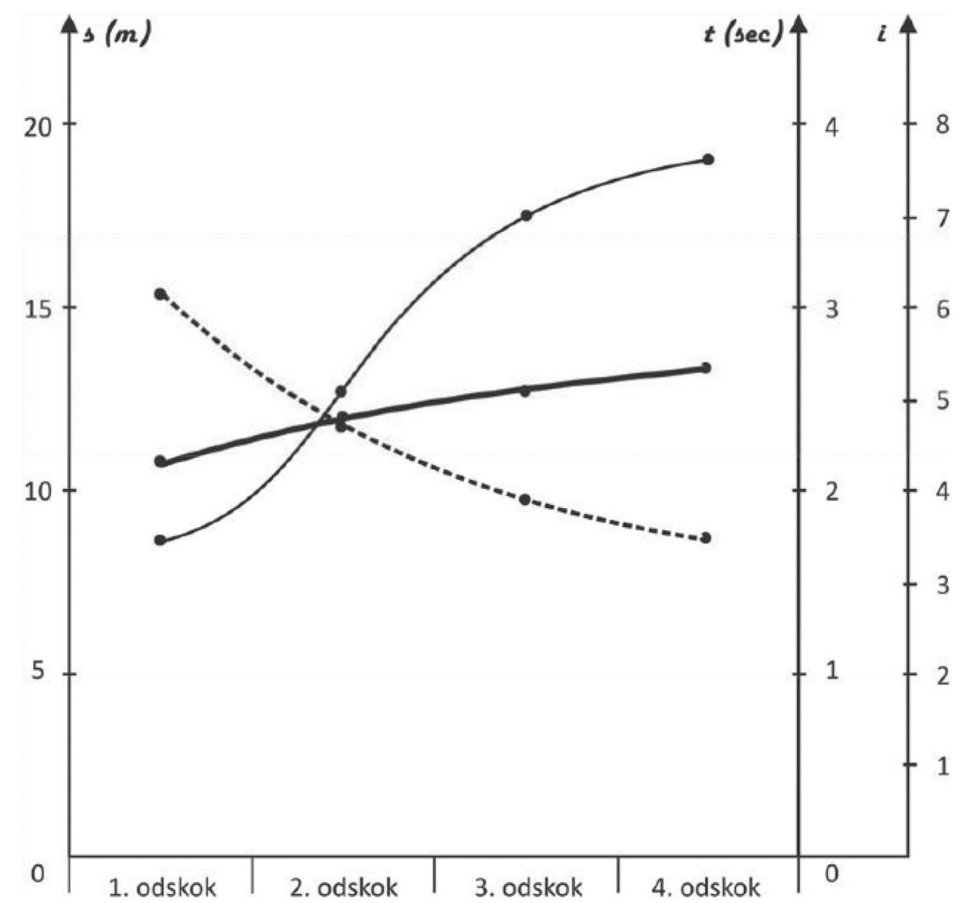

Legenda: Tanja linija: ukupno vrijeme trajanja (t); Deblja linija: ukupno pređeni put (s) Isprekidana linija: indeks $=\mathrm{s} / \mathrm{t}$

Dijagram 4. Ukupno vrijeme trajanja i pređeni put (standardni pritisak lopte)

U narednoj fazi prikazani su koeficijenti stonoteniske lopte standardnog pritiska, za svako vrijeme trajanje i za svaku postignutu visinu (Tabela 4.).

Tabela 4. Koeficijent repulzije

\begin{tabular}{cccccc}
\hline Pritisak & $\begin{array}{c}\text { Nakon prvog } \\
\text { odskoka }\end{array}$ & $\begin{array}{c}\text { Nakon drugog } \\
\text { odskoka }\end{array}$ & $\begin{array}{c}\text { Nakon trećeg } \\
\text { odskoka }\end{array}$ & $\begin{array}{c}\text { Nakon četvrtog } \\
\text { odskoka }\end{array}$ & $\begin{array}{c}\text { Prosječne } \\
\text { vrijednosti odskoka }\end{array}$ \\
\hline standardan & 0.45 & 0.77 & 0.84 & 0.79 & 0.72 \\
\hline
\end{tabular}

\section{Diskusija}

Većina kretanja u sportu se određuje prostorno vremenskim parametrima. Kretanje stonoteniske lopte u prostoru tokom vremena se najrealnije ocjenjuje planimetrijski, postavljanjem istraživačkih veličina u površinski prostor (Bjelica, 2014). Lopta, koliko god puta da se nakon spuštanja kretala vertikalno u slobodnom padu, nije imala vertikalan odskok od četiri sukcesivna odskakanja. Prisutnost asimetrije lopte i posljedice te asimetrije u velikoj mjeri su negativno uticale na određivanje visine kulminacionih tačaka. Koliko je ta asimetrija bila primjetna prilikom testiranja, još je bila primjetnija prilikom odskakanja lopte tokom eksperimenta. Da bi se mogle odrediti bar neke zakonitosti kod repulzije lopte, neophodno je odrediti dvije veličine: prostornu, odnosno visinu kulminacione tačke težišta lopte svakog odskoka s jedne, i vremensku, odnosno trenutak odskoka, s druge strane.

Prilikom sprovođenja ovog eksperimenta, testirana je stonoteniska lopta, za koje je proizvođač garantovao da je licencirana kao propisana. Prilikom odskakanja lopte asimetrija je bila primijetna, i negativno je uticala na određivanje kulminacionih tačaka. Stonoteniska lopta koliko god puta da se nakon spuštanja kretala vertikalno u slobodnom padu, nije imala vertikalan odskok od četiri sukcesivna odskakanja. Posmatrajući zbir putanja od trenutka ispuštanja pa do kulminacione tačke četvrtog odskoka lopte kao i trajanje odskakanja lopte od početka slobodnog pada pa do kulminacione tačke četvrtog odskoka, može se zaključiti da pređeni put i ukupno trajanje četiri suksecivna odskakanja najviše zavisi od standar- 
dnog (propisanog) pritiska.

Generalno gledajući, na osnovu prikaza kulminacionih tačaka u rezultatima došlo je do smanjivanja visine i vremena prilikom svakog odskoka. Na osnovu navedenog utvrđeno je kako se ponašaju visina i vrijeme trajanja odskoka stonoteniske lopte u odnosu na propisani (standardni) pritisak. Budući da kretanje lopte u predjelu kulminacionih tačaka relativno dugo traje, položaj lopte u tom predjelu zabilježen je u više tačaka, pa je stoga kulminaciona tačka kod svakog odskoka mogla da se odredi sa dozom nepreciznosti, i ta odstupanja ublažena su interpolacijom. Te pretpostavke bazirale su se na činjenici da je položaja lopte $u$ fazi odskoka bilo premalo, pa se nije moglo tačno definisati da li te pozicije pripadaju posljednjim trenucima prije sudara ili početnim trenucima odskoka nakon sudara sa tlom. Ove su se pretpostavke i potvrdile na osnovu stohastičkih ponašanja visine i vremena trajanja odskoka, nakon opservacije Dijagrama 1. i 2. Na osnovu grafičkog prikaza Dijagrama 3. mogu se vidjeti vrijednosti kulminacionih tačaka pojedinačnih odskoka u funkciji vremena. Indeks otpora vazduha lopte ukazuje na razlike otpora vazduha, zavisno od performanse lopte. Najveći indeks otpora vazduha je kod stonoteniske lopte, što potvrđuje činjenicu da je, pored veličine poprečnog presjeka, masa tijela značajan faktor u stvaranju otpora vazduha. Nakon izračunavanja koeficijenta repulzije za stonotenisku loptu, za odskok utvrđeno je, sem u nekoliko izuzetaka u kojima je lopta zbog netolerantne asimetrije odskakala sa velikim otklonom od vertikale, da je koeficijent repulzije stonoteniske lopte 0.72 .

\section{Acknowledgements}

There are no acknowledgements.

\section{Conflict of Interest}

The authors declare that there are no conflicts of interest.

Received: 13 September 2018 | Accepted: 17 October 2018 | Published: 29 October 2018

\section{References}

Bjelica, D. (2005). Sistematizacija sportskih disciplina i sportski trening. Podgorica: Crnogorska sportska akademija.

Bjelica, D. (2008). Sportski trening. Nikšić: Fakultet za sport i fizičko vaspitanje. Bjelica, D. i Fratrić, F. (2011). Sportski trening: teorija, metodika i dijagnostika. Nikšić: Fakultet za sport i fizičko vaspitanje.

Bjelica, D. (2014). Repulzija sportskih lopti naučna studija. Podgorica: Crnogorska sportska akademija i Univerzitet Crne Gore.

Bjelica, D., Popović, S., Gardašević, J., \& Krivokapić, D. (2016). Dependence of Football Repulsion on the Pressure Within This Sport. Journal of Physical Education and Sport, 16(2), 452-8.

Bjelica, D., Popović, S., \& Gardašević, J. (2016a). Dependence of basketball repulsion on the pressure within this sport. Journal of Physical Education and Sport, 16(1), 125-31.

Bjelica, D., Popović, S. i Gardašević, J. (2016b). Modeli fizičke pripreme vrhunskih sportaša i doziranje opterećenja. Zbornik radova 14. godišnje međunarodne konferencije "Kondicijska priprema sportaša" (185-189). Zagreb: Udruga kondicijskih trenera Hrvatske.

Bjelica, D., Popović, S. i Gardašević, J. (2016c). Opći principi planiranja i programiranja fizičkih priprema sportaša. Zbornik radova 14. godišnje međunarodne konferencije "Kondicijska priprema sportaša" (190-192). Zagreb: Udruga kondicijskih trenera Hrvatske.

Bjelica, D., Popović, S., \& Gardašević, J. (2016d). Pressure dependence of handball repulsion within this sport. Journal of Physical Education and Sport, 16(2), 1078-1083.

Bjelica, D., Popović, S., Tanase, G.D., \& Gardašević, J. (2017). Dependence of female ball in handball repulsion on the pressure within this sport. Acta Kinesiologica, 11(1), 67-72.

Bjelica, D. \& Gardašević, J. (2018). Volleyball elastic properties depending on ball pressure. Sport Science, 11(1), 45-51.

Gardašević, J., Vasiljević, I., \& Bojanić, D. (2015). Six-week preparation period and its effects on coordination transformation with football players under 16. Book of Abstracts 11th International Scientific Conference Management, Sport, Olympism (36), Beograd: Fakultet za menadžment u sportu, Alfa univerzitet.

Gardašević, J., Bjelica, D., Milašinović, R. \& Vasiljević, I. (2016). The Effects of the Training in the Preparation Period on the Repetitive Strength Transformation with Cadet Level Football Players. Sport Mont, 14(2), 31-33.

Gardašević, J., Bjelica, D., \& Vasiljević, I. (2016a). Six-Week Preparation Period and its Effects on Transformation Movement Speed with Football Players Under 16. Sport Mont, 14(1), 13-16.

Gardašević, J., Bjelica, D., \& Vasiljević, I. (2016b). The Effects of the Training in the Preparation Period on the Repetitive Strength Transformation With Cadet Level Football Players. Book of Abstracts of the 13th International Scientific Conference on Transformation Processes in Sport "Sport Performance" (43), Podgorica: Montenegrin Sports Academy.

Gardašević, J., Bjelica, D., \& Vasiljević, I. (2017a). The strength of kicking the ball after preparation period with U15 football players. Book of Abstracts of the 14th International Scientific Conference on Transformation Processes in Sport "Sport Performance" (65-66), Podgorica: Montenegrin Sports Academy.

Gardašević, J., Bjelica, D., \& Vasiljević, I. (2017b). The Strength of Kicking the Ball after Preparation Period with U15 Football Players. Sport Mont, 15(2), 39-42.

Karimi, A., Kudo, S., Razaghi, R., \& Navidbakhsh, M. (2015). Measurement of the mechanical properties of the handball, volleyball, and basketball using DIC method: a combination of experimental, constitutive, and viscoelastic models. Sport Sciences for Health, 11(3), 295-303.

Oliveira, A., Valladares, N., Vaz, L., \& Joao, P. (2016). Evaluation of Scoring Skills and Non Scoring Skills in the Brazilian Super League Women's Volleyball. Montenegrin Journal of Sports Science and Medicine, 5(2), 2531.

Sermaxhaj, S., Popović, S., Bjelica, D., Gardašević, J., \& Arifi, F. (2017). Effect of recuperation with static stretching in isokinetic force of young football players. Journal of Physical Education and Sport, 17(3), 1948-1953. doi: 10.7752/jpes.2017.03191.

Zagatto, A., Kondrić, M., Knechtle, B., Nikolaidis, P., \& Sperlich, B. (2017). En ergetic demand and physical conditioning of table tennis players. A study review. Sports Sciences, 36(7), 724-731. 